\title{
AC 2008-2726: A STUDENT OVERVIEW IN PRACTICAL SUSTAINABILITY
}

\section{Cindy Orndoff, Florida Gulf Coast University}

Dr. CYNTHIA (CINDY) ORNDOFF is an Associate Professor in the Department of Environmental and Civil Engineering. She received a B.S. in 1984, an M.S. in 1997 and a Ph.D. in 2001, all in Civil Engineering from University of Illinois, Urbana-Champaign. Prior to her coming to FGCU she was an Assistant Professor in Civil and Environmental Engineering at the University of Missouri, Columbia. She has taught courses in infrastructure management, planning, introduction to transportation and construction management. She has a passionate interest in sustainability as well as policy which led to her initiating and developing a course in contract law for engineers. Dr. Orndoff joined FGCU with more than 10 years of field experience and has worked in multiple areas of civil engineering with the Illinois Department of Transportation. Her areas of expertise include sustainability, asset management, decision-making, economic development, performance assessment, policy, organizational assessment, and public relations. Her engineering research incorporates economics, public administration, public policy, political science, public finance, planning, and sociology aspects. Key to her engineering research is the focus on multiple stakeholders and their considerations in the decision -making process. Dr. Orndoff's research has always been application-based encompassing engineering leadership, engineering education, and practice issues. Dr. Orndoff has participated on several professional committees, including Disadvantage Business Enterprise Committee for the Transportation Research Board, American Society of Engineering Educators as well as regional economic development initiatives. She served as vice-chair of the Engineering Management and Business Practices Committee and vice-chair and chair of the Engineering Management and Leadership Committee for the American Society of Civil Engineers. 


\title{
A Student Overview In Practical Sustainability
}

\begin{abstract}
One purpose of teaching sustainability in an engineering curriculum is to foster civic responsibility and develop informed citizens who are responsible to their professions, communities, posterity and to the world. This paper provides a series of five reports authored by undergraduate students which portray the student perspective on green construction practices and how the implementation of such practices impact on sustainability in real world applications. Students explore various techniques for construction professionals, property owners and policy makers that promote the aesthetic and economic benefits of green construction. Investigating real world examples, students discover how the public policy arena affects sustainability. This paper demonstrates engineering students developing consideration of high standards and ethics in regards to engineering service delivery via sustainability practices. The students expand on the social impact of implementing sustainability and how the related public policy can advance such efforts. The goal was to not only expose the students "green" building but to investigate the implementation while encouraging them to visualize the possibilities of further implementation of sustainability practices and to integrate sustainability concepts into the engineering mindset regardless of the project.
\end{abstract}

\section{Introduction}

One purpose of teaching sustainability in an engineering curriculum is to foster civic responsibility and develop informed citizens who are responsible to their professions, communities, posterity and to the world. This paper involves a guided student study of sustainability in engineering. Essentially students began to investigate how we as engineers utilize and implement existing research and products into delivery to the customer particularly in terms of green engineering. Due to rising costs in energy, engineering services delivered need to be self sustaining whether new or reconstructed.

The course provided the students the ability to investigate and document green construction practices and its impact on sustainability in real world applications. This papers overviews the student exploration of various techniques used by construction professionals, property owners and policy makers that promote the aesthetic and economic benefits of green construction. The research gathered by the students resulted in the following reports produced by undergraduate students and compiled by graduate students. The compendium of construction practices from the student perspective that bring to light the advantages of implementing green construction include the following five sustainability topical areas: Educating Property Owners and Buyers, A Greener World - Green Construction Practices to Rebuild and Preserve, Greener Roofs for A Greener Community, Benefits of Protective Construction Practices and Tree Conservation through Proper Construction Techniques. 


\section{Educating property owners/buyers on long-term management/maintenance}

This essay will investigate the issues around building for greener communities. In particular, this essay will focus on educating owners of businesses and residential property owners, on the background and techniques that make a building green and how they aid in creating a cleaner, safer and greener community. In exploration of these techniques, we may find new plans or designs that will affect a positive format.

Conventional construction techniques are proving to be detrimental to the environment and becoming an inadequate way to sustain the environment. A method of construction that is becoming more and more popular is the trend to build "greener". Building greener can mean employing different styles or approaches, but all have a similar goal and concept, which is to improve the environment while construction is in progress or striving for improvements in post construction. Typical building construction, manufacturing and demolition are all contributors to environmental problems. "In the United States, buildings account for:

- $36 \%$ of total energy use

- $\quad 65 \%$ of electricity consumption

- $\quad 30 \%$ of greenhouse gas emissions

- $\quad 30 \%$ of raw waste output (equal to 136 million tons annually)

- $\quad 12 \%$ of potable water consumption

- A typical 1700 sq. ft. wood frame home requires the equivalent of clear cutting onceacre of forest."

With detrimental impacts of inputs such as these, not much is being done to change the way we build. This is why educating developers and home buyers on how to build and maintain green buildings and communities is becoming essential.

\section{Impact to property owners}

Indirect impacts to owners of business, as well as property owners, are becoming more relevant as recent studies show dramatic impacts of what environmental affairs can do to productivity. Approximately a third of US buildings are rated with poor indoor quality. This is an astounding fact given that most employees spend 90 percent of their work time indoors, costing US businesses about $\$ 15$ billion in productivity losses annually. "By the year 2010, another 38 million buildings are expected to be constructed in the U.S. bringing our country's total to over 100 million. The challenge is to build those new buildings, and renovate the older ones, in ways that reverse these unhealthy trends." ${ }^{1}$ The challenge is getting the construction industry to accept and employ greener practices. The major way to meet this challenge is to build green. Building green has endless positive results that may include preserving natural habitats, ecosystems, watersheds; protecting water and air quality; reducing waste and greenhouse gases; thus creating better outdoor and indoor environments for people to live and work in. As a business owner or property manager, this is extremely beneficial as a green building can essentially lower operating costs and reduce maintenance and replacement due to more durable materials. As a residential property owner, the use of non-toxic materials is important to protect children from diseases. 


\section{Techniques that make a product Green}

Based on Global Green USA's Green Building Resource Center, there are four basic resources that invite ways to build green: save energy, contribute to safe, healthy indoor environments, protect natural resources and reduce building's impact on the community. As a business or residential property owner, it is extremely important to determine which of these recourses is most important in your area. Depending on specific environments and issues in your community, it may be more important to focus on maximizing one area as opposed to another. As an owner it is essential to find out how a building works and what functions you need it to form. Finding ways a building can be environmentally friendly is an asset to the future of production for an owner's facility. An example of conserving energy could be a dual pane window that is strategically placed for energy reduction in both the winter and summer months. In decision making for building greener, there are design considerations that need to be made. "Some design considerations that will help you choose the right materials include building orientation use patterns, durability, and local availability" 1 Green building material may be difficult to identify. To contrast this problem and help property owners and managers, GreenSpec has been developed, a database that screens its products based on tested results. These results filter into five categories: saving energy, protecting natural resources, safer indoor environments, conservation of water, and reducing the building's impact on the community. ${ }^{1}$

\section{Save Energy}

As a property owner/manager, it is essential to save energy to cut production costs and maximize the energy source to be as efficient as possible. Ways to promote saving energy could include product groups that reduce heating and cooling loads, use less energy, and products that produce energy. This definition explains how important it is for the property owner to investigate ways in his/her location to save energy.

“A 'green' building places a high priority on health, environmental and resource conservation performance over its life-cycle. These new priorities expand and complement the classical building design concerns: economy, utility, durability, and delight. Green design emphasizes a number of new environmental, resource and occupant health concerns." 2

\section{Protect Natural Resources}

It is intriguing to many owners how simple and beneficial it is to build green. In many cases, building green does not cost much more that traditional building and can bring a premium in price in the long run. These higher prices or margins are developed because contractors are able to use recycled natural recourses. Another way to increase margins is to reduce the waste of materials in the demolition and building process. Through construction management and owner knowledge, similar environmental goals can be reached.

"Reducing the environmental impact of the construction process begins with managing necessary demolition responsibly. Many materials can be salvaged for reuse or collected for recycling, often by specialized waste receivers. These services can actually save money for the contractor or owner, because transportation costs and dumping fees are reduced and some items are worth 
cash. Protecting the site from undue damage to soils, vegetation and air quality and preventing storm water contamination during excavation and construction is the second part of responsible construction. The third part is ensuring that construction waste is minimized, recyclables are recovered and toxic releases on site are minimized. The final part is ensuring that building occupants are protected from construction-related health hazards during renovations or during first occupancy after completion." 2

Water conservation has always been important in the construction industry. Although there are many water conservation laws while building, there are still some green building techniques that can help in the decision process. An example of a green strategy for a building design would be to install dual-flush toilets or under-sink flow restrictors. It is important to consider the landscape and use of native plants or drought resistant plants to conserve outside waste water.

\section{Contribute to a Safe Indoor Environment}

It is a crucial concept to maximize the productivity of employees inside of a building, since most US employees spend around 90 percent of their time indoors. Products that do not release significant pollutants in the building are essential. Basically building and painting with non toxic substances such as Green Label carpets and pads could be a wise selection in furnishing the inside of a building. Things as simple as effective ventilation equipment could suffice for a green building. Also installations of smoke detectors with carbon monoxide detectors are a smart combination for a healthy indoor environment.

"Indoor air quality is often poorest in buildings immediately after construction is complete; however few regulations exist to protect building occupants during this period. Liquid finishes such as paints, sealers and adhesives release volatile gases during curing that cling to carpets, gypsum board and other porous surfaces and are then released over time. Dusty operations, such as finishing gypsum board, installing insulation and ceiling tile, and sanding or grinding hard floor surfaces leave large residues of nuisance or hazardous dust that accumulate on interior finishes, in ceiling cavities and ducts, to be released later into the occupied zone. A proactive approach that minimizes occupant exposure to health hazards through careful construction procedures will go far toward reducing complaints and limiting owner and contractor liability." 2

\section{Reduce Buildings' Impact on the Community}

Through ambitious acts of property managers and developers, building greener will have positive implications on the community. In the demolition stage, the salvation and reuse of building materials is a way to develop green habits. "Products that mitigate the effects of storm water runoff, such as permeable plastics, green roofs and cisterns; products that provide easy access to alternative modes of transportation such as bike racks and storage units, as well as products that do not require chemical pesticides or treatment." 1

The preceding categories are merely the beginning in the development of greener communities. Through owners' and property managers' education and commitment of protecting the environment, improving quality of life, and promoting sustainability, construction could see a drastic turn in the demand for green building in the upcoming decade. In order to fulfill this 
commitment, local communities have to adopt a set of requirements and recommendations to encourage the development of "green" buildings without forcing excessive costs or other burdens upon developers, building owners or occupants. These communities could also take the initiative to develop Green Building Guidelines that will aid in the explanation of possible ways to achieving green building goals.

\section{Greener World - Green Construction Practices to Rebuild and Preserve}

During the construction phase, the vegetation surrounding the site is often neglected or viewed as an obstacle. Certain landscape attributes may indeed be an issue such as the tree in the middle of the proposed work site. Although the necessity to remove such an obstacle seems obvious, introducing new vegetation in the area may not be the priority for the owner. This has a negative effect on the surroundings overall, yet the problem has a solution. The earlier destruction of trees and bushes cannot be undone, but it is possible to reestablish a greener community by introducing new plants and/or trees in the previously developed areas. There are many factors that might affect the process, such as the conditions under which certain plants may develop, as well as the location of the site. This presentation is an attempt to discuss the possible solutions and ways to re-green previous construction areas, as well as practices to preserve vegetation.

"While it may be necessary to clear the proposed construction site from trees that may prevent or hinder the construction process, the importance of vegetation around the post-construction area should be recognized. Many trees are removed by contractors solely for their convenience; perhaps to provide shorter or more convenient access to the site or create a materials storage area." It is, however, possible to introduce a way of handling a post-construction re-vegetation of the site, as well as practice preservation techniques during construction.

"Trees and vegetation are essential to the earth's atmosphere, because of the important role they play in the greenhouse effect. Greenhouse gases are natural gases such as carbon dioxide or methane that are emitted in large quantities as a result of certain human activities. During the past century the emission of those gases rose tremendously. Since the beginning of the industrial revolution, atmospheric concentrations of carbon dioxide have increased nearly $30 \%$, methane concentrations have more than doubled, and nitrous oxide concentrations have risen by about $15 \% . " 7$ The increased amount of greenhouse gases in the earth's atmosphere contributes to the amount of heat the atmosphere can trap, thus increasing earth's overall temperature. According to the National Academy of Sciences, the Earth's surface temperature has risen by about 1 degree Fahrenheit in the past century, with accelerated warming during the past two decades."7

What makes plants important, in this respect, is their ability to act as "sinks". A "sink" is a reservoir that uptakes a chemical element or compound from another part of its cycle. ${ }^{7}$ In other words, plants are able to consume carbon dioxide from the atmosphere, thus reducing the greenhouse effect. As previously mentioned, most of today's emissions come from human activities, such as burning fossil fuels to generate electricity and power cars.

Groundwater runoff is becoming an increasing problem in growing communities. The amount of water that is absorbed by the immediate environment is decreasing with the construction of new buildings and roads. What little natural soil is left cannot absorb the excess water. The 
impact of the rain drops disconnects soil particles from the pedons, and washes them into nearby streams and rivers, causing soil erosion and water pollution through sedimentation. Different practices, such as preservation of trees and sedimentation nets, can be implemented to protect against excess runoff, soil loss, and sedimentation of water sources. The preservation of trees on construction sites helps protect the environment, along with increasing the value of the property. When trees or forests are removed, there is a major impact on the amount of water that actually reaches the ground. In a developed deciduous forest, up to $40 \%$ of rainfall is intercepted by the canopy. It is also important to notice that larger trees have a widespread root system, which, together with roots of the neighboring trees, forms a type of net that is very efficient at stabilizing soil around the trees. This helps prevent landslides, soil erosion, and other undesirable soil deformations near a building. Thus, trees can provide a drier construction site, lessen drainage costs, and reduce the need for sedimentation nets.

The re-greening process can take many different forms, from reviving vegetation that was destroyed during construction to introducing completely new plant species to the recently developed area. One choice is to preserve what vegetation is possible, only removing plants that hinder the construction process directly and later re-plant the trees and bushes that had to be removed. While it seems to be the simplest choice, it is in fact a process that requires care and caution. For almost any type of construction, a major part of the process is excavation and trenching. It is very easy to severely damage a tree root system, particularly if major roots are chopped off in the process. Removing a tree's large roots cuts down the nutrient and water supply of the tree and may result in a slow but steady decline and death of the tree. Another major issue is stability of a tree. With some of the major roots destroyed, a tree is more likely to fall and possibly damage the building and cause injuries. If trees are to be preserved and revived, it is essential to avoid damaging major roots as much as possible. Also, postconstruction care may be needed to ensure survival of a tree. "Trees that have had their root systems reduced during the excavation can benefit from timely watering and fertilization. In times of drought, watering may be essential to the survival of trees that have lost substantial portions of their roots. Trees so affected need time to regenerate an adequate root system, and that may take several years."

When introducing new vegetation into an area, it is essential to consider the terrain and climate of the region. For example, a common misconception is that establishing grass on a rocky, highaltitude site constitutes an alternation for the natural state of the land. ${ }^{5}$ It is important to determine which plants belong to the given ecosystem and are able to adapt to changes caused by construction. For newly planted seeds, mulch is used to keep topsoil in place and retain moisture, as well as provide shade. ${ }^{5}$ Soil needs to be rough and contain enough nutrition for newly planted trees to be able to adopt and grow. The soil surface not covered by rock, litter, or already existing vegetation ${ }^{4}$, may not present a suitable habitat for many trees. As a general rule, the less the topography is altered, the better - both for the environment and cost-wise. ${ }^{5}$

Altering an ecosystem may not only make it difficult to introduce new trees but alter already existing plants, particularly if the ecosystem is a forest type with several inter-dependant layers. Cutting down larger trees, for instance, will remove shade and will likely cause a decline of smaller shrubs and bushes. "Country club ... built its club house and parking lot within a wooded area and thinned the woods, leaving the larger, and then beautiful, white ash towering over the 
parking lot. Within a year the ash were showing signs of decline, and within 10 years they were all gone. White ash and many other species will not tolerate that type of environmental change once the trees are established in a natural stand." 6 Similarly, placing a young tree that requires a lot of sunlight in shade will cause slowed growth of a tree.

It is best to avoid mixing two ecosystems unless it is certain that the two species can grow in the same area. For instance, some woodland trees tend to grow faster than others and may create an undesirable shade for a tree below. The numerous pine forests are a result of such exterminationthey dominate all other major trees that require sunlight, leaving only smaller shrubs. Weather needs to be taken into account as well. As an example, two different species that can grow under the same temperature and same amount of light may have totally different flood tolerance, which is the plant's ability to withstand water inundations for periods ranging from days to months. ${ }^{4}$ For re-vegetation of sites with heavy construction and greater pollution, it is best to pick tolerant, adaptive trees that can grow in a variety of soils. Trees with lower tolerance may be a good choice for residential areas where they can receive more attention and better care.

The construction industry needs to consider the re-vegetation of post-construction sites. Good, green construction practices can help prevent the need for re-vegetation. Vegetation may need to be removed from a work site while the construction is taking place, but restoring it is an important aspect of the construction process. Bringing the area back to its original state is essential for the ecosystem and surroundings. Besides providing a healthier environment, trees and plants offer a better look to the area. Re-greening post-construction sites can be a beneficial practice for every contractor to consider.

\section{Greener Roofs for a Greener Community}

Mankind has not, as of yet, learned how to effectively coexist with its natural surroundings. This becomes very apparent when looking at global warming, air and water pollution, deforestation, and the massive amount of waste that we produce on a daily basis. It will be imperative in the next several years that the global community comes together to solve these problems. Two of the many industries that will be affected are the construction industry and engineering/architect community. There are several "green" construction practices available today, but perhaps one of the most interesting and beneficial is that of "green roofs." Green roofs are basically a roof with a layer of vegetation and/or soil on top. They have many benefits, including the reduction of storm water runoff, air purification, reduction of ambient air temperature due to reflective surfaces, and energy conservation. Green roofs offer a first step for the design and construction industries to become environmentally friendly because of the many benefits that they offer.

There are many types of green roofs that are aesthetically beautiful and help make use of wasted roof space. The two basic types of green roofs are: intensive and extensive. Intensive green roofs have a deeper soil level that allows for large shrubs and even trees. Such a roof can be found on the Cannon Street Station in London, England. These types are obviously a large undertaking, and must be considered in the structural design. They also are not self sustainable and require an irrigation system. Extensive green roofs are more affordable and easily applicable in most cases. They consist of a thin growing medium, such as recycled aggregate or moisture blanket, placed on top of a waterproofed roof. Intensive green roofs can be grown, "harvested," 
and placed on the roof, or can be hydro seeded in-situ. A third, but slightly different variation, is the "green wall," which has been widely used in the US. Green walls promote vine and vegetation growth on the walls of a structure to conserve energy by providing shade and insulation. Green roofs can be traced through history, even to the Hanging Gardens of Babylon, and create a beautiful and natural space.

Perhaps the most desirable and marketable attribute of green roofs is that they conserve heating and cooling energy. The vegetated layer not only protects the roof from wind, frost, and mechanical damage (almost doubling the expected roof life), but it also acts as an excellent insulation layer. Green roofs keep houses cooler in the summer and warmer in the winter. As cited on the "Livingroofs" website, a Nottingham Trent University research project found that with a mean daily temperature of $18.4^{\circ} \mathrm{C}$, the temperature beneath an extensive green roof was $17.7^{\circ} \mathrm{C}$, while the temperature beneath a normal roof was $32^{\circ} \mathrm{C}$. The same Trent University study also found that with a mean daily temperature of $0^{\circ} \mathrm{C}$, the temperature under a green roof was $4.7^{\circ} \mathrm{C}$, compared to a normal roof which was $0.2^{\circ} \mathrm{C}$. Obviously, green roofs are very efficient at energy conservation. Additionally, a study in Chicago, Illinois, estimated that $\$ 100,000,000$ could be saved each year in air conditioning energy costs if all roofs were "greened." The insulation properties of green roofs are due to photosynthesis, evaporation, and evapotranspiration processes occurring within the vegetation and the soil layers.

For the same reason that they effectively regulate temperatures inside the building, green roofs also eliminate excess air temperatures outside the building which normal, reflective roofs create (called the albedo effect). So called "Urban Heat Islands" are created in big cities, where excess thermal energy increases the air temperature above and creates both ideal conditions for smog and abnormal weather patterns. In large cities, the temperature difference from the center of the city to the rural areas can be as large as $5^{\circ} \mathrm{C}$. Green roofs reduce this excess energy radiation and promote better air quality. Thus, the excellent energy conservation properties of green roofs are one major reason for considering and promoting them by the construction industry, engineering community, and global governments.

Green roofs are also very desirable in that they absorb and greatly reduce water runoff. Green roofs can store and evaporate rainwater in the soil medium and the vegetation. A study in Germany has shown that "during a 10mm rainstorm, 200 litres of rainwater fell on an $18 \mathrm{~m}^{2}$ extensive green roof and only 15 litres actually passed from the roof to the ground." Amazingly, only $7.5 \%$ of the rainwater passed through the system. The amount of water a green roof can hold is dependent on its type and size, but Livingroofs reports that "In summer green roofs can retain 70-80\% of rainfall and in winter they retain between 25-40\%." Mark Leslie for Environmental Design + Construction's website reports that "they absorb up to 90 percent of the water that lands on them." This property could drastically reduce the impact of storm water runoff and localized flooding. This same runoff also is a major cause of soil erosion, which leads to pollution of streams and other water sources. Thus, green roofs remedy a wide variety of environmental problems.

Green roofs are directly environmentally friendly in that they create vegetation that purifies the air and promote biodiversity by recreating local habitats for bugs, spiders, and birds. Grass and other green vegetation absorb $\mathrm{CO}_{2}$, a known greenhouse gas, and release $\mathrm{O}_{2}$ into the atmosphere. 
This is very conducive to animal life in that it recycles the air that we depend on. It also helps remedy ozone production by reducing the carbon dioxide and the "Heat Island" effect. The vegetation also removes heavy metals, organic compounds, and particle pollution from the air, which could eventually end up in the water system. Biodiversity can be achieved by using local substrates and materials, as well as local vegetation, to create the green roof/habitat. Using local materials allows for local and possibly scarce species of bugs and birds to have a new, reclaimed habitat. Thus, green roofs directly and indirectly help the environment.

There is already a growing demand for green roofs in both the global community and in the United States. Many countries have already initiated incentives for using green roofs. Germany already has a \$191 million green roof industry, setting standards for other countries. Since 2000, Germany has erected over 30 million square meters of green roofs ${ }^{5}$, and more than 80 cities offer incentives or government grants to promote this construction technology. ${ }^{14}$ Toronto, Canada promotes the technology because of the "Urban Heat Island", with its own City Hall having a green roof.

Leaders in the United States include Chicago, Seattle, and Portland, Oregon. Seattle promotes green roof for their storm water runoff properties, to protect the water environments of the salmon there. "'Green roofs meet a number of our objectives in the city,' said Sadhu Johnston, assistant to the mayor for green initiatives in Chicago. "First is that they help to moderate temperature in the city. The urban heat island is a significant issue for all big cities. They also help address storm water issues by absorbing storm water and holding it for a 48-hour period... They help with creating habitat for species in the city. On our City Hall green roof, you will see dragonflies, crickets, birds and butterflies. It's an interesting component. The last thing for us, as a city, is that green roofs extend the life of a roof from 15 to 20 years to 50 or 60 years. So it is a really good long-term investment." ${ }^{\prime 4}$ There are predictions that this technology will take off here in America, especially with the development of modular systems that make retrofitting and replacement/maintenance much easier.

Green roofs have many benefits, both in cost efficiency and in environmental terms. They are energy efficient for heating and cooling, reduce storm water runoff and erosion, reduce both air and water pollution, promote biodiversity, increase the roof life significantly, and are aesthetically pleasing. It is up to the construction and design community to be catalysts for this beneficial technology. New building can easily implement simple green roof systems and still see these benefits. Old buildings can easily be retrofitted with modular green roofs. To be a global leader, the US must follow the footsteps of countries like Germany and apply this technology, for the good of our environment's future.

\section{$\underline{\text { Benefits Protective Construction Practices }}$}

Having a landscape that is properly maintained can be beneficial for businesses, homes, and even entire cities. An appropriately designed and maintained landscape will increase the property value, preserve energy consumption, and present the property in a manner that is aesthetically pleasing. Although a homeowner may be more concerned with increasing the property value or cutting back on energy costs, a business owner or city would also want to protect their investment, especially when it can be as simple as supporting the landscape with the relatively 
little care that it requires. Landscaping, like property, generally appreciates in value over time. For instance, a tree that has been planted will increase in value as it grows, and it will require little maintenance relative to the value that it will accrue. In fact, in a survey conducted by the Weyerhaeuser Corporation, landscaping was reported to have increased home values by an average of $15 \%$, which, according to Money magazine, means about a $100 \%$ to $200 \%$ recovery of landscaping costs.

In addition to the large financial return on property that it produces, a healthy landscape can save money by reducing energy consumption and helping to reduce pollution. In one year, a threeinch diameter tree is capable of filtering out the carbon dioxide pollution that is caused by an automobile being driven ten miles. Yet, the actual amount of pollution that any one plant filters out is difficult to determine, as it is based on other factors including location and environment. A three-year study conducted by the US Forest Service in the downtown Chicago area found that planting 95,000 trees benefited the surrounding communities by $\$ 38$ million over a thirty-year period. Approximately $\$ 9$ million of that was due to these trees removing polluting agents, such as ozone, carbon monoxide, and sulfur dioxide. The enormous monetary return that was generated by these trees in Chicago far outweighs the cost of maintaining them. The city of Davis, California, found similar results, which indicated that the nearly 24,000 public street trees that the city maintained provided $\$ 1.2$ million in net annual environmental and property value benefits. The city's trees produced benefits that offset the cost of them by a ratio of 3.8 to 1 .

Energy costs of a home, or any structure, can be reduced through proper maintenance and design of a landscape. Proper design of a landscape is just as important as proper maintenance. In the design process, a tree that is placed in the appropriate spot, depending on the location of the structure and the climate, can reduce energy costs year round. In the summer, the cost of cooling can be reduced by a tree that is in a position to shade the structure. More specifically, a tree is used most effectively if it blocks the sun later in the day rather than in the morning, or if it is used to block the sun from any large windows. That same tree will lose its leaves in the winter and let the sunlight through to help heat the home when the weather is cold. Proper placement of trees can also cut heating costs by acting as a wind buffer. Evergreens are especially good at blocking cold, winter winds if placed on the side of the structure that is most often assaulted by winds.

The aesthetic improvements that a well-groomed, well-designed landscape provides can be significant to a home, business, or city because it shows that the people living or working there have not only cared for their yard, but also for their home or business. While pleasant to look at, a good landscape can also enhance the image that a property exudes. When a guest or potential client visits a home or place of business, the first thing they see when they approach is the landscaping. Since procurement of new clients is what many businesses strive for, proper landscape maintenance could be viewed as a means of protecting an investment. Homeowners are also obviously concerned with protecting their investment, but they are accustomed to separate values being placed on the structure and the property as far as tax purposes are concerned. When buying a house, though, these two separate entities are looked at together as a package. How well the structure and property mesh, plays a major role in the possible return that a seller could collect. Landscaping is the connection between the structure and property. Therefore, a healthy, beautiful landscape that was designed specifically for a structure or 
property will make the package more desirable for buyers. In a very similar manner, cities would want their landscapes to be aesthetically pleasing not just to retain existing residents, but to attract new residents and businesses.

It has also been shown that a properly maintained landscape can benefit a single home or an entire community; the rewards outweigh the costs in number and in value. There are procedures that can reduce the already relatively low cost of maintenance even further. Two such procedures are proper design of landscapes and landscape-friendly construction practices. Proper design of a landscape actually determines the amount of maintenance it will need. Based on many different factors, a landscape can be designed to be nearly maintenance free; however, cost and appearance are often trade-offs for maintenance.

One factor taken into account in the design phase is the plant selection and placement. Good plant selection and placement means not choosing a plant that will outgrow the space it has been allocated and not placing it too close to things it might interfere with, such as sidewalks and power lines. Being aware of these problems during design will eliminate the need for constant trimming, and promote healthy plant growth. A healthy plant also needs to be designed for an appropriate environment. The more suited the plant's needs are to its environment, the less care it will require. Environmental considerations that could affect a plant's health are the exposure to sunlight and wind, soil types, moisture conditions, local climates, and common pests. If the plant is able to avoid pests that are severely detrimental to its well-being, there will be less need for many costly pesticides.

The interface between different elements of landscape design is another important factor. Examples of interfacing of elements that would interfere with each other include trees and power lines or plants with walkways and lawns. Plants that are too close to the lawn are not only in danger of being damaged by weed eaters or mowers, but they might also prevent the most efficient means of mowing the lawn. Using larger mowers for large lawns is more effcicient. Landscape obstacles, due to poor design, can decrease mowing efficiency. One more design consideration is the use of geotextiles. An application of these geotextiles is to lay it underneath bedding areas where it acts as a barrier and a surface stabilizer. These specially designed fabrics are meant to block weeds from entering the bedding area, thus reducing the need for herbicides, which can be costly. They also separate any other unwanted plants or materials from growing, as well as preventing erosion.

Finally, there are measures that can be taken during construction to preserve the natural landscape. Rather than trying to start a whole new landscape after construction is complete, contractors could stray from the common construction process and try to preserve some of what is already there. In the preconstruction phase, proper design once again plays an important role; only now it is construction design as opposed to landscape design. During the planning and design phase is when the decision is made as to what plants or trees, if any, can be left and how to build around them. Careful selection of plants and trees is best to protect the ones with optimum health, size, location, condition, species, and age for the final project. Also, any complete design drawings or documents must include these protected areas. 
During construction, using fencing, signs, or some type of barrier establishes protection zones so these zones aren't disturbed. Tying back trees, or using a series of ropes or flat straps to pull the branches back out of the way of construction, is another option. This method resembles how Christmas trees are bound for transportation. Tying is a good method for short term protection, but if bound long term, the shape of the tree could be altered and the inner leaves and branches of the tree could be killed off due to lack of rain, light, and air. Another problem with this method is that the ropes can get too taut and tear branches or strip bark. Fencing is a simple and easier method of protection. It creates a protection ring around the tree, with the ring being equal to the largest diameter of the canopy plus one to three feet. This is particularly useful when budgets are an issue, or there are plants underground that have not yet grown, such as perennials. This ensures that the area where the plants are will not be disturbed. Communication and education are also important for ensuring the preservation of these protected landscapes. The construction crew, especially any equipment operators, need to be informed of not only the existence and location of the protection zones, but also of the importance of being cautious. Preserving plants and trees is not the only way to minimize the destruction of the existing landscape. Protecting the topsoil and areas with desirable soil structure is highly desirable. The topsoil can be removed before grading to be replaced later on, or even sold where it can be put to good use somewhere else. The soil helps to determine the health of the landscape. Although these precautions to preserve some green space seem like an added headache, they are well worth it because a finished project with a mature landscape is much more marketable than one with a young, vulnerable landscape.

To prevent damage to the existing landscape, methods like transplanting can also be used. Transplanting was originally used to bring mature trees to areas where trees did not exist, like urban areas and parks. This technique can now be used to move trees away from construction areas to better protect them. Once transplanted in a new area, the tree must stay in the ground for one year, and a great deal of attention must be paid to the tree to ensure survival. If the tree is properly cared for, the survival rate for such a tree is near $100 \%$. Of course, this method requires proper planning. If a tree is in the way of construction, and it needs to be moved, a plan involving the construction path needs to be developed. If the contractor were to start building on the side of the house away from the tree, then once all the large equipment has been removed from that side of the house the tree can be transplanted on the finished side. This will also prevent construction delays.

The importance of a healthy landscape has already begun to influence the use of construction methods that preserve nature. In the long term, these newly adopted methods will be more favorable for the environment and hopefully influence similar methods in other aspects of life, such as transportation and manufacturing. In this case, it is accurate to say that properly maintaining a landscape is basically just taking on the responsibility of caring for the environment. Furthermore, it is becoming more apparent every day that the Earth's natural resources are finite. The solution to this problem is to preserve what is left of those resources while trying to find alternatives. While it has been shown that preserving natural resources has many financial benefits, such as increasing property value, reducing energy costs, and reducing pollution, it is the benefits for which no price can be assigned that are the most important. Those benefits are the aesthetic value and, more importantly, the life-sustaining value that the environment offers. 


\section{Tree Conservation through Proper Construction Techniques}

When preparing for and performing a construction project, it is important to regard trees as an important aspect of the overall project. Trees can make a nice addition to a beautiful environment once the construction is done. They are a vital part of communities, enhancing the appearance of an area, reducing noise, cutting energy costs, screening unattractive views and attracting many species of wildlife

Trees produce positive effects on our environment. Trees reduce air pollution, noise pollution, light pollution, soil erosion, water runoff and climate control. By removing $\mathrm{CO}_{2}$ from the air, trees release oxygen, making the air cleaner. Although all types of vegetation do this, trees carry a more profound effect since they generally deal with greater volumes of air. Air pollution is also improved by trapping particulate matter on branches and leaf surfaces. This creates a less harmful atmosphere. To put this in perspective, a test showed that streets without trees have around 100 times as much dust in the air as streets with trees. ${ }^{27}$

Noise pollution may not be as import to our environment, but may be irritating. This problem is more common in larger communities where higher levels of noise are produced. Barriers can reduce noise pollution by deflecting sound waves in different directions. Sound reduction may also be attributed to the amount of humidity in the air. Trees can reduce sound levels by acting as barriers, absorbing sound waves, and adding humidity to the atmosphere. Light pollution, in the form of direct sunlight, can be reduced by mature trees. Shade may be offered giving other forms of vegetation opportunities to grow. ${ }^{27}$

Trees can reduce soil erosion in two ways, as windbreakers and as soil stabilizers. The large root structure of mature trees holds soils in place decreasing erosion. Figure 1 shows the effect of different types of land on the amount of sediment per square mile is lost per year.

\begin{tabular}{|l|l|}
\hline Land Type & $\begin{array}{l}\text { Sediment Lost } \\
\text { (tons) }\end{array}$ \\
\hline forestland & 50 \\
\hline urban/suburban & $50-100$ \\
\hline farmland & $1,000-5,000$ \\
\hline $\begin{array}{l}\text { land stripped } \\
\text { for } \\
\text { construction }\end{array}$ & $25,000-50,000$ \\
\hline
\end{tabular}

From Table 1, it is obvious how much non-vegetated land suffers from soil erosion. Along with soil erosion, trees reduce amounts of water runoff. Water runoff has become a significant concern as denser residential and commercial sites are developed. Due to these developments, the peak discharge of streams is increasing. Trees help to decrease the amount of water runoff by breaking the impact of rain drops, allowing for a greater infiltration time into the topsoil. When water runoff is reduced, less erosion occurs downhill or downstream. ${ }^{27}$

Significant effects have been observed on temperature and energy use due to the presence or absence of trees. Communities populated with large trees experience lower temperatures, saving 
up to 20-25\% in home energy use. A lack of trees and vegetation can create a "heat island effect." Approximately five to ten percent of the current electric demand in cities is spent on cooling buildings just to compensate for the heat island effect. Nationally, the hourly cost may be as high as $\$ 1$ million.

The first step in preserving trees during construction is making a plan, as a well-laid plan can save time and money in the future. The most important consideration is determining which trees are to be saved and which are not. Criteria can be used to select a tree to be saved. Some of the characteristics of a healthy tree are a solid trunk and full live branches. If a tree turns to fall colors early or loses it leaves early in the season, it is probably diseased and needs to be destroyed. It is also a good practice to analyze the ratio of canopy versus trunk size. A healthy tree will have $60 \%$ canopy to $40 \%$ trunk.

In addition, younger trees will adapt to construction changes better than older trees. Another consideration is the sensitivity of the tree to root disturbance and soil compaction. Some trees are more sensitive to root cuts than others. Too often builders like to start with a clean slate and will completely clear a lot before construction. Carefully inventorying and inspecting the trees on the lot using the criteria above allows for the builder and the owner to agree on which trees will remain. Then the architecture and placement of the house can reinforce that plan and protect the selected trees.

During construction, it is wise for the builder to rope off areas where tree roots are likely to exist. This will keep the heavy equipment from harming the roots of the trees. Wood chips, which can be made from the trees destined for removal, can be used in high traffic areas to protect the soil from becoming too compacted and damaging roots. Once the trees to be saved are determined, a plan must be made to protect these trees. Some simple preconstruction steps are to 1) mark trees to be saved with a surveyor's flag or ribbon, 2) apply mulch around the trunk of the tree, 3 ) prune all the dead wood in the tree in order to reduce the amount the tree must support while under stress, 4) construct a barricade to establish a tree protection zone (a minimum of one foot from the tree for each one inch diameter of the tree trunk), 5) place tree protection signs on the barricade, and finally 6) include a tree protection clause in the construction contract (include penalties for violations of the clause and damage to the trees).

Once the plan has been made and preliminary precautions to save the trees have been met, construction may begin. Damage to trees may still occur even when preliminary precautions are met. These things include lowering the current grade, soil damages including soil compaction, digging trenches, severing roots, increasing the current grade, and injuries on the tree caused by construction equipment. It is important to protect the root system of trees in order to preserve the trees during construction. Approximately 90 percent of the root system is in the top three feet of the soil. The area directly below the branches of the tree is where most of the root system will be located. One way to avoid severing roots is to reroute the utilities. If going around the tree is impossible, the damage may be reduced by going beneath the roots. Often, severing roots is unavoidable despite the best plans. When cutting the roots is necessary, it is helpful to water the tree a few days before the cut and right after the cutting. Also, if the cuts are made with hand tools there is a quick, clean cut. This will promote a quick recovery of the wound. Some trees can lose up to 50 percent of its root system and still survive, but the optimum loss is 20 percent. 
Damages to the soil during construction can harm or kill trees. Soil compaction is the biggest reason urban trees are killed during construction. Trees need loose soil so the roots can grow, obtain oxygen, and absorb water. Storage of building materials, heavy machinery, and increased foot traffic can cause soil compaction. To prevent soil compaction, storage areas for construction equipment need to be located away from the trees that are to be saved. Also, walking areas that are clearly marked and away from the trees helps to save the trees. The best solution for soil damages is prevention but when this cannot be done, the next best thing is protection. Some protective measures to be taken are to spread out several inches of wood chips around the root zone and to bridge the root areas with plates of steel. Parking places for workers need to be clearly marked. Other damages to soil can be harmful to the trees. Chemicals must be handled carefully to avoid spills at the site or a fine may ensue from the Environmental Protection Agency or its local counterpart. Therefore careful attention needs to be whether or not to clean paintbrushes and tools on the site. It is vital that all chemical wastes be hauled away from the site for proper disposal. Careful monitoring of the soil will ensure that the $\mathrm{PH}$ of the soil is altered too much. To prevent this, alkaline clays and limestone are not s good choice for fill or paving.

To prevent damage while digging trenches, avoid digging during hot, dry weather. Also, keep the trees watered before and after digging. It is best to only dig trenches on one side of the tree and at a certain distance away from the trunk of the tree. To calculate this distance, the following formula can be used: Dbh $\mathrm{x} 0.5$ feet $=$ the minimum distance from the tree to the start of the trench (in feet). Dbh is the diameter of the tree 4.5 feet off the ground. This is the minimum distance, but the further away from the tree, the better chance the tree has for survival.

It is often necessary to change the grade during construction. Increasing the grade near a tree can be extremely harmful to the tree. No more than 24 inches of soil need be added under a tree, but adding 6 inches or less will help to ensure the safety of the tree. It is key that the soil added not be allowed to touch the trunk of the tree because it could cause rot, which will most likely kill the tree. To keep the soil from touching the trunk, a retention wall can be built around the trunk at least three feet away from the trunk. Also, breaking up the top 3 to 6 inches of soil allows for better contact between the fill and the soil surface. The loosening of the soil will also prevent some of the compaction damage to the roots.

Lowering the grade will be less likely to cause damage than increasing the grade. Not disturbing soil within 3 feet of the trunk is essential to the health of the tree. Building a retaining wall and spreading mulch around the tree may also help protect the tree. It is important to repair any damages caused by equipment to the trunk immediately. Pruning broken branches right away is also critical. If 50 percent of the bark on the trunk has been removed, the tree will likely die and will need to be removed. If only a little bark has been damaged, the wound will heal with a little care. Long term maintenance of the remaining trees needs to be acknowledged. Irrigation and mulch around the bases along with planting of shrubbery will help promote recovery of the tree's roots. A hired tree specialist would provide a yearly evaluation to determine the health of the trees and to determine if fertilization or other chemical processes are needed to protect them. 
After construction is finished, the health of the tree ought to be monitored for at least 3 to 5 years. This is how long it may take a tree to recover from the damages done during construction. Any wounds that the tree received from the construction process require proper cleaning such as removing the loose bark leaving a smooth edge around the wound. Also, it is vital that the trees be watered immediately after the work is completed. Fertilization is optional after construction and depends on the amount of tree damage. If roots were cut, the tree must not be fertilized for at least a year. The canopy of the tree should not be thinned out until one to two years after construction has stopped. After the two years, all the dieback that has occurred can be removed. A few years after construction, if the tree dies, people often blame the death on something else, but it is usually damage from the construction process that causes it. If the trees receive proper care, there is a good probability remain healthy.

Awareness is the key to saving trees around construction sites. People need to realize that saving trees is an important part of construction, and it needs to be worked into the construction process. Avoiding damages to trees may not be the easiest path during the construction process, but it is well worth the effort. Healthy trees will make a beautiful addition to the newly constructed area and can increase property value of a site 9 to 27 percent. Planning and simple preventive steps can prevent future problems with the trees. If taken care of, the trees can be an important part of a completed construction project making it healthier and more attractive.

\section{Conclusion}

As the result of this exercise, students demonstrated knowledge in incorporating green construction practices and promoting the sustainability of aesthetic, as well as economic benefits to the environment. The fostering of civic responsibility and developing informed citizens who are responsible to their professions, communities, posterity and to the world was evident throughout the entire project. The student investigation into how we as engineers utilize and implement existing research and products into delivery to the customer particularly in terms of green engineering turned into the start of an area of special interest. The investigation and documentation exercise into green construction practices and its impact on sustainability in real world applications was very gratifying to all involved. The application of such practices is applicable to both commercial and residential construction; single-family dwellings or entire communities and individuals and public policy makers.

Class discussions that occurred after each presentation fostered insight into public policy and the engineering profession. In fact a major outcome of this project was the unanimous sentiment that there should be more green building policy initiatives. Through this exercise students realized just how much the engineering professional can possibly interrelate with public policy. Moreover as a result of investigating the benefit of implementing green building principles, the students realized on their own the fact that they as an engineer can help to influence public policy. This learning experience for undergraduate engineering students challenged their preconceptions and opened their minds to the future of engineering, serving as a guidepost for a potential career direction. Some may even pursue an elected office. Educational activities such as this one can help persuade a student that their technical knowledge can be a force in the public decision making arena. 


\section{Bibliography:}

[1] Building Green Resource Center; "Why Build Green", http://www.globalgreen.org/gbrc/whygreen.htm

[2] Santa Monica Green Building Program, "Conserve today Preserve Tomorrow", 2004

http://www.greenbuildings.santa-monica.org/index.html

[3] O'Haver, Walk, Kitiyanan, Boonyarach, Harwell, and Saatini; "Packed Column and Hollow Fiber Air Stripping of a Contaminant-Surfactant Stream." ASCE Journal of Environmental Engineering, 2004

[4] Ogle, Englert, and Gibbs; "Glossary of Terms for Use in Plant Materials", USDA - Natural Resources

Conservation Service, Boise, Idaho, 2001

[5] Boulder County Land Use Department; "Revegetation”, Boulder, CO, 1998

http://www.co.boulder.co.us/lu/pdf/reveg.pdf\#search='revegetation

[6] T. Davis Sydno; Trees and Home Construction "Minimizing the impact of construction activity on trees", U.S.

Environmental Protection Agency, http://www.epa.gov

[8] Fisette, Paul and Ryan; "Saving Trees During Construction: Protecting the roots from digging and compaction is critical." The Journal of Light Construction, 2004 http://www.homebuilders.org

[9] Srinivas, Hari; "What is a green or sustainable building?"2004, http:// www.garc.org/uem/green-construction

[10] Treescape; "After Construction", http://www.treescape.org/newpages/afterconstruction.html

[11] Treescape; "Before Construction", http://www.treescape.org/newpages/beforeconstruction.html

[12] Treescape; "During Construction", http://www.treescape.org/newpages/duringconstruction.html

[13] Treescape; "Why Save Trees", http://www.treescape.org/newpages/whysavetrees.html

[14] Leslie; "Green Roofs Meet Environmental Objectives", Environmental Design + Construction, 2005

http://www.edcmag.com

[15] Frith, Matthew and Gedge; http://www.livingroofs.org/index.html

[16] Green Roofs; “Green Roofs for Healthy Cities', http://www.greenroofs.org

[17 ] Ard, Jeff and IPM Associates, Inc; "Fundamentals of a Low Maintenance Integrated Pest Management

Approach to Landscape Design”, Landscape Design for IPM and Low Maintenance, 1990-1999

http://www.efn.org/ ipmpa/des-cnsd.html

[18] Campbell; "Landscaping Makes Cents", Storey Communications, Inc., Pownal, Vermont 1997

[19] Elmendorf, Gerhold, Kuhns, and The Pennsylvania State University; "A Guide to Preserving Trees in

Development Projects", PLANT-Landscape Maintenance, 1999 http://pubs.cas.psu.edu/FreePubs/pdfs/uh122.pdf

[20] Reno Lawn and Landscape; "Commercial Landscape Management Services", Reno Lawn and Landscape, 2002 http://www.renolawn.com/commercial.shtml

[21] Seignot and Lockwood; "Interior Planting: A Guide to Plantscapes in Work and Leisure Spaces", Gower, Burlington, Vermont, 2000

[22] Bracewell; "Protecting Existing Trees During Construction", http://www.sustland.umn.edu/implement/protecting_trees.html

[23] Home and Garden Information Center Clemson; "Protecting Trees During Construction." http://hgic.clemson.edu/factsheets/HGIC1002.htm

[24] South Carolina Forestry Commission; "Protecting Trees During Construction."

http://www.state.sc.us/forest/refcons.htm

[25] Miller, Rathke, and Johnson; "Protecting Trees from Construction Damage: A Homeowner's Guide",

University of Minnesota Extension Service, St. Paul, MN, 1998

www.extension.umn.edu/distribution/housingandclothing/DK6135

[26] Burban and Anderson; "Storms Over The Urban Forest" USDA Forest Service, St. Paul Field Office 1994

http://www.na.fs.fed.us/spfo/pubs/uf/sotuf/chapter_5/regreening_the_community.htm

[27] Brabec; "Trees Make Cents", 2000 http://www.scenicflorida.org/lscmakecents.html

[28] National Association of Home Builders; "Tree Preservation Ordinances.” http://www.nahb.org

[29] Dooley; "First Things First: Considering Green Land Development", 2001

[30] Fisette and Ryan; "Preserving Trees During Construction", 2002 http://www.umass.edu

[31] Johnson, Miller, Rathke; "Protecting Trees From Construction Damage: A Homeowner's Guide", 2005

http://www.extension.umn.edu

[32] McMindes and Vogel; "Residential Construction Contractor's Guide", 2001 http://peakstoprairies.org 